\title{
Problems of Spiralling Costs
}

From Dr. Raymond Greene, Consulting Physician, Royal Northern Hospital, London, and Chairman, Heinemann Medical Books Ltd., London

This, dear Mr. Editor, is a question only answerable by a question. What do you mean by "too" dear? They are dear all right, but do you mean that they are too dear for people to buy? This, I am glad to tell you, is not true. They are bought in ever increasing quantities throughout the world, though least in countries with currency difficulties. In the "developing countries" British publishers are greatly helped by the Cheap Book Scheme organized by the English Language Book Society and the Central Office of Information. Under this scheme chosen books are sold at a third of their normal price. In the U.S.A. the sale of British medical books is large. The small firm of which I have the honour to be chairman exports about $60 \%$ of its products, a good thing from the point of view of the country's balance of trade.

Or do you mean too expensive for students to buy? Apparently this again is not so, especially since the dawn of the paperback. A large number of students hold special grants for buying books and some of them actually use their grants for this purpose and not on banners or pints at the local. Moreover, there are libraries in every medical school. They cannot afford to buy every medical book but they buy the best of them. There are publishers of whom one suspects that they must rely entirely on library sales, so esoteric are their products. Such books are sold in such small numbers that they are bound to be expensive enough to cover the cost of their production.

Or do you mean that the cost of medical books has risen to such an extent that the lining of the publishers' pockets is unduly thick? Here again the answer is "no." In the last decade the cost of printing has risen by $70 \%$, of paper by $30 \%$, and of binding by $30 \%$. Packing and warehousing expenses have risen rapidly. Postage on letters, proofs, and the books themselves has increased. The ready cash that the publisher must provide is harder to get and borrowing is more expensive.
It is sometimes forgotten that the risks of publishing are great. Even an expert specialist publisher may make an unexpected loss on an individual book that he knows to be a good one, and for reasons of prestige or the public good he occasionally publishes a book expecting a loss. Often the profit is not proportional to the large capital expended or to the work involved, though now and again he may make a killing (and the author as well). The author, of course, gets his royalties on every copy sold from the day of publication, long before the publisher can hope for his first returns. There was a time when he could hope to recoup by a large sale of books to the general practitioner but more and more the demand is for specialist books with a narrow appeal. The standard textbook with a big, ready-made sale is certainly not too dear, for the numbers keep the price down, but new books are always a risk ; calculation of their likely sales is very speculative. Shareholders expect a fair return on their investments.

From the publisher's angle the rapid advance of medical knowledge is a danger. The "life" of a book is short; it soon becomes out of date and a new edition (and still further capital investment) may be demanded before the whole of the first edition has been sold. There are few books that are not in need of revision within three years, a few even before they appear in the bookshops.

It has been suggested that too many medical publishers are chasing too small a readership. There may be something in this, but knowledge must be disseminated and competition is a good thing, even though it increases risk and therefore price.

Indeed on all counts it is difficult to answer "yes" to the question posed, or to think of any action likely to reduce the present price of medical books, daunting though it is.

RAYMOND GREENE.

\section{British Medical Association}

\section{Annual Scientific Meeting, 7-10 July}

The first part of the report of the Scientific Meeting appeared in last week's B.M.F. (19 fuly, p. 162). The report is concluded below.

\section{Mental Defectives in N.E. Scotland}

\section{Thursday, 10 fuly}

The chairman of the session on genetic studies of mental deficiency in North-east Scotland was Professor S. C. Frazer (Aberdeen), who said that such studies were of importance in three main ways. Firstly, there was little information about many of the causes of mental defect; secondly, management could be improved in some cases if more was known of causation; and, thirdly, genetic counselling of parents with an affected child could be scientifically based if the genetic nature of a defect was understood.

Speaking on the aims and methods of the survey, Dr. GeORGE INNES (Aberdeen) said that the geography and integrated medical services of North-east Scotland made it parti- cularly suitable for epidemiological study. The population was largely captive $-85 \%$ of residents at the last census having been born in the area and a further $9 \%$ elsewhere in Scotland. Three main objectives of the study had been to determine case rates and morbidity patterns, to collect operational data on which to plan services for the mentally deficient, and to build up a data bank as a basis for more detailed later studies.

Dr. Innes then gave figures for those with an intelligence quotient below 70 , obtained in a preliminary survey carried out in April 1966. This had disclosed a total of 2,887 mental defectives, with a marked preponderance of males (7.1 per 1,000 population) over females (5.1 per 1,000 population). Ascertained subnormality was low in the preschool years, then rose steadily to a peak of about
10 per 1,000 population at about 19 , before declining again with increasing age to only about 2 per 1,000 in those over 70 . To some extent these variations probably reflected difficulties in collecting data; in general, the highest rates were found in areas with well-developed services. About $60 \%$ of all mental defectives were classified as high-grade, $35 \%$ as medium, and less than $5 \%$ as low-grade, two-thirds of the last group being cared for institutionally in contrast to only a quarter of high-grade defectives. The proportion in institutions rose steadily with age, from $8 \%$ at age 10 to $85 \%$ at 80 . Of all mental defectives in the survey one-third were cared for in institutions and two-thirds in the community, where $40 \%$ attended special schools, etc., while $60 \%$ were looked after solely by the family.

Concluding, Dr. Innes said that the cause of mental deficiency was not known accu- 